\title{
Effect of Cnidii Rhizoma on nitric oxide production and invasion of human colorectal adenocarcinoma HT-29 cells
}

\author{
KYUNG-SOO NAM ${ }^{1}$, BYUNG GEUN HA ${ }^{2}$ and YUN-HEE SHON ${ }^{2}$ \\ ${ }^{1}$ Department of Pharmacology, College of Medicine, Dongguk University, Gyeongju, Gyeongsangbuk-do 780-714, \\ ${ }^{2}$ Bio-Medical Research Institute, Kyungpook National University Hospital, Daegu 700-721, Republic of Korea
}

Received February 12, 2014; Accepted October 2, 2014

DOI: $10.3892 / 01.2014 .2660$

\begin{abstract}
Colorectal adenocarcinoma is the most common type of gastrointestinal cancer. Colon adenocarcinoma is a major health problem worldwide due to the high prevalence and mortality rates associated with the disease. The majority of colorectal carcinomas are adenocarcinomas, which originate from the epithelial cells of the colorectal mucosa. HT-29 cells, which originate from human colon adenocarcinoma, are used as an in vitro model to investigate the effect of malignant transformation on the expression of cellular constituents and functions of the intestinal epithelium. Nitric oxide (NO) is a signaling molecule, which is involved in inflammation and carcinogenesis. It has been reported that enhanced inducible NO synthase (iNOS) activity and the resulting NO concentrations in human colon carcinoma contribute to tumor progression and vascular invasion. The present study investigates the effect of pro-inflammatory cytokine-induced nitric oxide $(\mathrm{NO})$ production and iNOS expression on the invasion of human colorectal adenocarcinoma HT-29 cells, and the effect of extract from Cnidii Rhizoma on NO production and the invasiveness of HT-29 cells. Treatment of HT-29 cells with cytokines, $100 \mathrm{U} / \mathrm{ml}$ interferon $\gamma, 10 \mathrm{ng} / \mathrm{ml}$ interleukin- $\alpha$ and $25 \mathrm{ng} / \mathrm{ml}$ tumor necrosis factor $\alpha$ was found to increase NO production. Pretreatment of the cells with Cnidii Rhizoma $(0.1-5 \mathrm{mg} / \mathrm{ml})$ resulted in an inhibition of cytokine-induced NO production and iNOS expression. The invasiveness of HT-29 cells through Matrigel was significantly increased by treatment with cytokines. Cnidii Rhizoma inhibited the invasiveness of cytokine-treated HT-29 cells through the Matrigel-coated membrane in a concentration-dependent manner. Matrix
\end{abstract}

Correspondence to: Professor Yun Hee Shon, Bio-Medical Research Institute, Kyungpook National University Hospital, 50 Samduk 2-ga, Jung-gu, Daegu 700-721, Republic of Korea E-mail: yhshon@hmail.knu.ac.kr

Key words: colorectal adenocarcinoma HT-29 cells, invasion, Cnidii Rhizoma, nitric oxide, matrix metalloproteinase-2, pro-inflammatory cytokines metalloproteinase (MMP) activity in HT-29 cells increased following the treatment with cytokines, and pretreatment of the cells with Cnidii Rhizoma inhibited cytokine-induced MMP-2 activity. These results provide sufficient information for the further development of Cnidii Rhizoma as an antitumor metastatic agent for the treatment of colon cancer.

\section{Introduction}

Nitric oxide (NO) is an important bioactive signaling molecule that is significant in numerous physiological processes in the cardiovascular, neurological and immune systems. However, increased NO production may also contribute to the pathogenesis of a variety of disorders, including various cancers, such as breast, cervical, gastric, colorectal and head and neck cancers (1). The formation of NO from arginine is catalyzed by three types of NO synthase (NOS): Endothelial NOS (eNOS), neuronal NOS (nNOS) and the inducible isoenzyme (iNOS) (2). iNOS expression is generally induced by inflammatory stimuli and is responsible for the production of large quantities of NO. It has been reported that the synthesis of $\mathrm{NO}$ is induced by cytokines in certain human carcinoma cell lines (3). A previous study has suggested that a high expression of iNOS is associated with the aggressive behavior of colorectal adenocarcinomas (4), however, the biological significance of $\mathrm{NO}$ in malignant tumors remains unclear.

Cancer cell invasion and metastasis are complex multi-step processes that involve cell adhesion, degradation of the extracellular matrix by proteolytic enzymes and motility factors that influence cell migration (5). Matrix metalloproteinases (MMPs) are significant in the degradation of the extracellular matrix and the MMP family consists of $>20$ proteolytic enzymes (6). MMP production appears to be a marker for cancer cells with elevated metastatic potential (7) and the activation of MMP activity has been detected in colon carcinoma (8).

Cnidii Rhizoma is the dried root of Cnidium officinale Makino and has been reported to exhibit antitumor activity in ddY mice (9), inhibit liver and lung metastasis of tumor cells in vivo (10) and exhibit anti-angiogenic activity in renal glomerular capillary endothelial cells, chick embryo chorioallantoic membrane and rat cornea (11).

$\mathrm{N}$-(3-(aminomethyl)benzyl)acetamidine (1400W), a nontoxic novel NOS inhibitor, is the most selective inhibitor of 
iNOS (12). 1400W has been reported to be effictive in the treatment of colonic injury in an experimental model of colitis in rats (13). Recently, the potency and selectivity of 1400W, as an inhibitor of iNOS and cytokine release modifier, have indicated a potential use for $1400 \mathrm{~W}$ in cancer therapy (14).

Colorectal cancer is the second most common cause of cancer in women (9.2\% of diagnoses) and the third most common in men $(10.0 \%)$ worldwide (15). It is a multifactorial disease etiology, which includes genetic factors, environmental exposures, such as diet, and inflammatory conditions of the digestive tract. In Western Europe and the USA the most common type of colon cancer is adenocarcinoma, which accounts for $98 \%$ of all cases. Lymphoma and squamous cell carcinoma occur less frequently (16). Adenocarcinoma is a malignant epithelial tumor, originating from the superficial glandular epithelial cells lining the colon and rectum. Conventional adenocarcinoma is characterized by glandular formation, which is the basis for histological tumor grading (17).

The present study investigates the ability of pro-inflammatory cytokine-induced NO to modulate the invasiveness of human colorectal adenocarcinoma HT-29 cells, which is a cell line mainly used as an in vitro colon epithelial cell model to investigate absorption, transport and secretion by intestinal cells, and the effect of the extract from Cnidii Rhizoma on NO production and invasiveness of HT-29 cells.

\section{Materials and methods}

Preparation of Cnidii Rhizoma extract. Cnidium officinale Makino root was collected in Jeong-seon, Republic of Korea. Specimens (no. 00C-37) were preserved by air-drying the roots and were deposited in the herbarium of the Intractable Disease Research Center (Dongguk University, Gyeongju, Republic of Korea). Cnidii Rhizoma (60 g) was extracted using $400 \mathrm{ml}$ distilled water for $3 \mathrm{~h}$. The extract was filtered and the $200 \mathrm{ml}$ filtrate was concentrated in vacuo, lyophilized using a Freezezone Console Freeze Dry System (7755040; Labconco, Kansas City, MO, USA) and stored at $-20^{\circ} \mathrm{C}$ prior to use. The mean yield of extract was $6.9 \%$ of the dried ingredient weight.

Cell culture. The HT-29 human colon adenocarcinoma cell line (American Type Culture Collection, Manassas, VA, USA) was cultured at $37^{\circ} \mathrm{C}$ in a humidified atmosphere of $5 \% \mathrm{CO}_{2}$ in RPMI-1640 medium (Gibco-BRL, Carlsbad, CA, USA), supplemented with $10 \%(\mathrm{v} / \mathrm{v})$ fetal bovine serum (Gibco-BRL).

iNOS induction. To induce iNOS expression, subconfluent monolayers were cultured in serum-free medium for $24 \mathrm{~h}$. Growth-arrested cultures were treated with pro-inflammatory cytokines, $100 \mathrm{U} / \mathrm{ml}$ interferon $\gamma($ IFN- $\gamma$ ) (Sigma-Aldrich, St. Louis, MO, USA), 10 ng/ml interleukin-1 $\alpha$ (IL-1 $\alpha$ ) (PeproTech, Inc., Rocky Hill, NJ, USA) and $25 \mathrm{ng} / \mathrm{ml}$ tumor necrosis factor- $\alpha$ (TNF- $\alpha$ ) (R\&D Systems, Minneapolis, MN, USA), pro-inflammatory cytokines and $0.1-5 \mathrm{mg} / \mathrm{ml}$ water extract of Cnidii Rhizoma or $0.5 \mathrm{mM}$ 1400W (Sigma-Aldrich) in fresh medium without fetal bovine serum. After $48 \mathrm{~h}$, the supernatants were collected and the cells were harvested and lysed as previously described (18).
Nitrite assay. Nitrite, a stable-end product of NO production in HT-29 cells, was measured as previously described (19) in the supernatants obtained from the cell culture. The protein concentration of the supernatant was determined using a bicinchoninic acid protein assay kit (Sigma-Aldrich) with bovine serum albumin as the standard.

Western blot analysis. Using a 7\% SDS-polyacrylamide gel, electrophoresis was performed to analyze the protein from cell lysates and subsequently electrophoretically transferred to a polyvinylidene difluoride membrane. The membrane was treated with $5 \%$ non-fat milk for $1 \mathrm{~h}$ to block non-specific binding and probed with a rabbit anti-human polyclonal iNOS antibody (sc-651; Santa Cruz Biotechnology, Santa Cruz, CA, USA) at a final dilution of $1: 1,000$. The primary antibodies were detected using biotin-rabbit anti-mouse immunoglobulins G, A and M (heavy and light chains; Zymed, San Francisco, CA, USA) and alkaline phosphate-conjugated streptavidin, and were visualized using 4-nitro blue tetrazolium chloride or 5-bromo-4-chloro-3-indolyl-phosphate substrate (Promega, Madison, WI, USA).

Invasion assay. Cell migration through Matrigel-coated filters was measured using Transwell chambers (Corning Inc., Corning, New York, NY, USA) with $8 \mu \mathrm{m}$-pore polycarbonate filters coated with Matrigel matrix (BD Biosciences, Bedford, MA, USA) as previously described (20). HT-29 cells were seeded at a density of $0.5 \times 10^{4}$ cells/well in the upper compartment of each invasion chamber and incubated for $24 \mathrm{~h}$ in the absence or presence of $100 \mathrm{U} / \mathrm{ml}$ interferon (IFN)- $\gamma$ (Sigma-Aldrich), $10 \mathrm{ng} / \mathrm{ml}$ interleukin (IL)1- $\alpha$ (PeproTech, Inc.) or $25 \mathrm{ng} / \mathrm{ml}$ tumor necrosis factor (TNF)- $\alpha$ (R\&D Systems), plus extract of Cnidii Rhizoma $(0.1-5 \mathrm{mg} / \mathrm{ml})$ or 1400W (0.5 mM). Non-migrating cells on the upper surface of the membrane were gently scrubbed with a cotton swab, and the invading cells on the lower surface were fixed with $100 \%$ methanol and stained with hematoxylin and eosin $\mathrm{Y}$ solution (RICCA Chemical Company, Charlotte, NC, USA). The number of cells was counted under a microscope at a magnification of x100.

Gelatin zymography. A gelatin zymography assay was performed as previously described (20). The HT-29 cells were plated at a density of $5 \times 10^{6}$ cells/well in 6 -well plates. After $18 \mathrm{~h}$, the monolayers were rinsed three times with phosphate-buffered saline followed by exposure to $100 \mathrm{U} / \mathrm{ml}$ IFN- $\gamma, 10 \mathrm{ng} / \mathrm{ml} \mathrm{IL-} \alpha$ and $25 \mathrm{ng} / \mathrm{ml} \mathrm{TNF}-\alpha$, and extract of Cnidii Rhizoma (0.1-5 mg/ml) or 1400W (0.5 mM) under serum-free conditions for $24 \mathrm{~h}$. The conditioned media was collected, normalized to the cell number, mixed with $10 \mathrm{x}$ non-reducing sample buffer (EZ BioResearch LLC, St Louis, MO, USA), consisting of $120 \mathrm{mM}$ Tris- $\mathrm{HCl}$ (pH 6.8), 50\% (v/v) glycerol, 4\% (w/v) SDS, $28.8 \mathrm{mM}$ 2-mercaptoethanol and $0.2 \%(\mathrm{w} / \mathrm{v})$ bromophenol blue, and SDS-PAGE was subsequently performed using a gel containing $10 \%$ SDS and $0.1 \%$ $(\mathrm{w} / \mathrm{v})$ gelatin. The resulting gel was rinsed in $2.5 \%(\mathrm{v} / \mathrm{v})$ Triton $\mathrm{X}-100$ for $1 \mathrm{~h}$ and enzyme degradation was performed at $37^{\circ} \mathrm{C}$ for $18 \mathrm{~h}$ in $50 \mathrm{mM}$ Tris- $\mathrm{HCl}(\mathrm{pH} 7.5), 5 \mathrm{~mm} \mathrm{CaCl}_{2}$ and $0.04 \%$ $\mathrm{NaN}_{3}$. The gel was subsequently stained for 30 min using $0.05 \%$ Coomassie Blue in $45 \%$ (v/v) methanol combined with $1 \%$ 
A

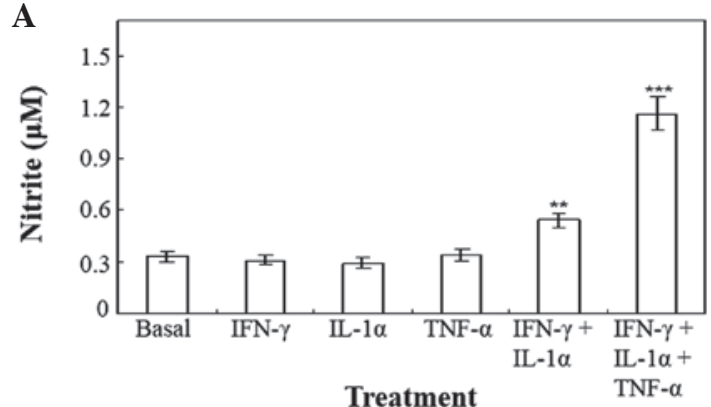

B

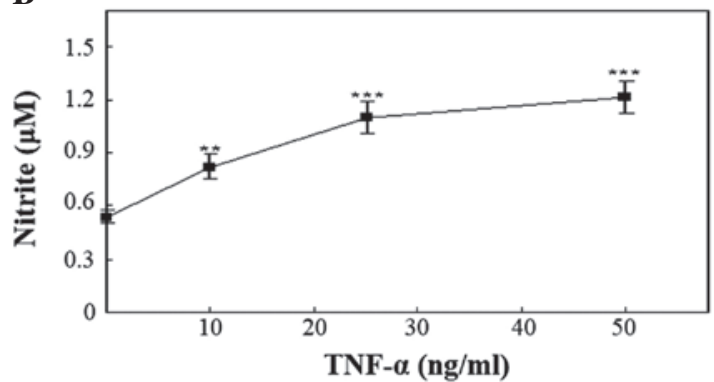

C

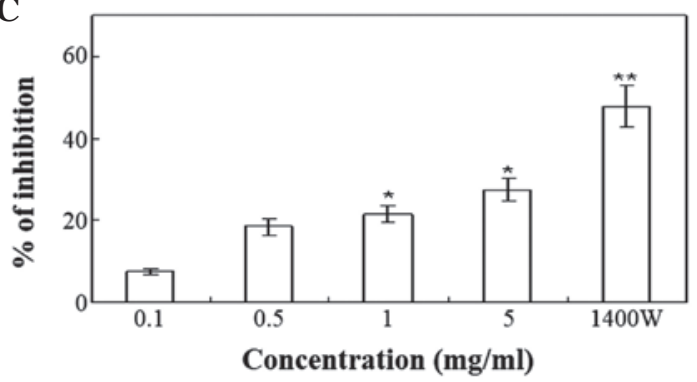

Figure 1. (A) Nitrite production by HT-29 cells following $48 \mathrm{~h}$ of treatment with cytokines. (B) Effect of $0-50 \mathrm{ng} / \mathrm{ml} \mathrm{TNF}-\alpha$ on nitrite production induced by $100 \mathrm{U} / \mathrm{ml} \mathrm{IFN-} \gamma$ and $10 \mathrm{ng} / \mathrm{ml} \mathrm{IL}-1 \alpha$ in HT-29 cells following $48 \mathrm{~h}$ of treatment. (C) Effect of water extract from Cnidii Rhizoma on cytokine-induced nitrite production in HT-29 cells following $48 \mathrm{~h}$ treatment with $100 \mathrm{U} / \mathrm{ml}$ IFN- $\gamma, 10 \mathrm{ng} / \mathrm{ml} \mathrm{IL-} 1 \alpha$ and $25 \mathrm{ng} / \mathrm{ml} \mathrm{TNF-} \alpha$. The data are presented as the mean \pm standard deviation $(\mathrm{n}=3) .{ }^{*} \mathrm{P}<.05,{ }^{* *} \mathrm{P}<.01$ and ${ }^{* * * *} \mathrm{P}<.005$ vs. control. 1400W, $0.5 \mathrm{mM} 1400 \mathrm{~W}$. IFN- $\gamma$, interferon- $\gamma$; IL1- $\alpha$, interleukin- $1 \alpha$; TNF- $\alpha$, tumor necrosis factor- $\alpha$.

(v/v) acetic acid, and destained in a solution containing $10 \%$ acetic acid (v/v) and $25 \%$ methanol (v/v).

Statistical analysis. The data were analyzed for statistical significance using Student's $t$-test. $\mathrm{P}<0.05$ was considered to indicate a statistically significant difference.

\section{Results and Discussion}

Induction of NO production in HT-29 cells. Upon stimulation with the vehicle for $48 \mathrm{~h}$, the resting HT-29 cells produced basal levels of nitrite (Fig. 1A). The pro-inflammatory cytokines, IFN- $\gamma(100 \mathrm{U} / \mathrm{ml})$, IL-1 $\alpha(10 \mathrm{ng} / \mathrm{ml})$ and TNF- $\alpha$ (50 ng/ml), did not affect the production of nitrite when added alone to HT-29 cells (Fig. 1A). The minimum requirement for enhanced nitrite production was the combination of IFN- $\gamma$ and IL-1 $\alpha$ (Fig. 1A), while other combinations of cytokines were ineffective. The addition of TNF- $\alpha$ to the combination of IFN- $\gamma$ and IL-1 $\alpha$ produced an approximately two-fold

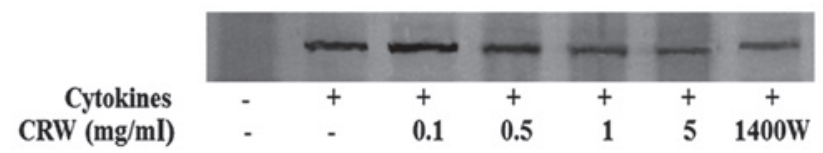

Figure 2. Inhibitory effect of water extract from Cnidii Rhizoma on the inducible nitric oxide synthase protein expression induced by $100 \mathrm{U} / \mathrm{ml}$ interferon- $\gamma, 10 \mathrm{ng} / \mathrm{ml}$ interleukin- $1 \alpha$ and $25 \mathrm{ng} / \mathrm{ml}$ tumor necrosis factor- $\alpha$. CRW, water extract from Cnidii Rhizoma; 1400W, 0.5 mM 1400W.

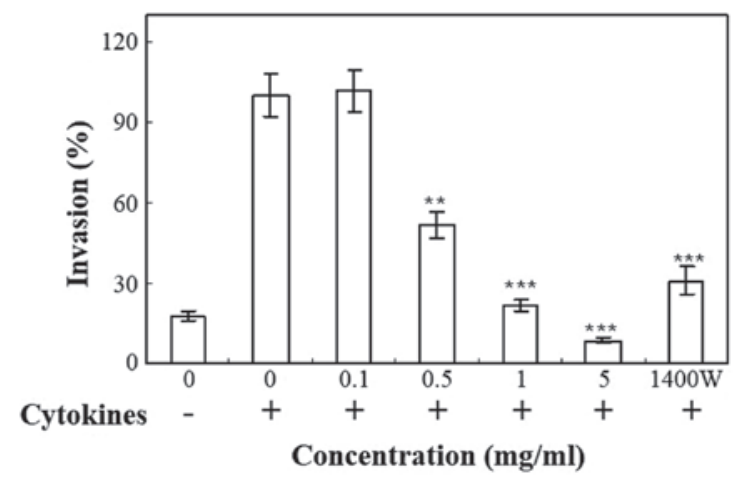

Figure 3. Effect of water extract from Cnidii Rhizoma on the invasiveness induced in HT-29 cells by $100 \mathrm{U} / \mathrm{ml}$ interferon- $\gamma, 10 \mathrm{ng} / \mathrm{ml}$ interleukin- $1 \alpha$ and $25 \mathrm{ng} / \mathrm{ml}$ tumor necrosis factor- $\alpha$. The data are presented as the mean \pm standard deviation $(\mathrm{n}=3) .{ }^{* *} \mathrm{P}<.01 ;{ }^{* * * *} \mathrm{P}<.005$ vs. control. 1400W, $0.5 \mathrm{mM} 1400 \mathrm{~W}$.

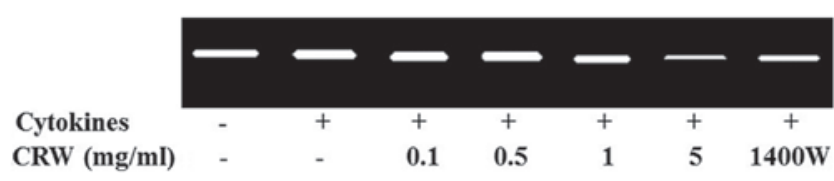

Figure 4. Effect of water extract from Cnidii Rhizoma on cytokine-induced MMP-2 activity in HT-29 cells. Gelatin zymography was used to detect MMP-2 activity in conditioned media obtained from HT-29 cells grown with cytokines $(100 \mathrm{U} / \mathrm{ml}$ interferon- $\gamma, 10 \mathrm{ng} / \mathrm{ml}$ interleukin- $1 \alpha$ and $25 \mathrm{ng} / \mathrm{ml}$ tumor necrosis factor- $\alpha$ ), cytokines plus water extract from Cnidii Rhizoma (CRW; 0.1-5 mg/ml) or 0.5 mM 1400W.

enhancement in IFN- $\gamma$ and IL- $1 \alpha$-induced nitrite production at $48 \mathrm{~h}$ (Fig. 1A). Various concentrations of TNF- $\alpha(0-50 \mathrm{ng} / \mathrm{ml})$ in the presence of the combination of $100 \mathrm{U} / \mathrm{ml} \mathrm{IFN}-\gamma$ and $10 \mathrm{ng} / \mathrm{ml}$ IL-1 $\alpha$, induced a concentration-dependent enhancement of nitrite production (Fig. 1B). Pretreatment of the cells with $\geq 5 \mathrm{mg} / \mathrm{ml}$ Cnidii Rhizoma or $0.5 \mathrm{mM}$ 1400W, exerted an inhibitory effect on the production of nitrite induced by treatment with $100 \mathrm{U} / \mathrm{ml}$ IFN- $\gamma, 10 \mathrm{ng} / \mathrm{ml} \mathrm{IL-1} \alpha$ and $25 \mathrm{ng} / \mathrm{ml}$ TNF- $\alpha$ (Fig. 1C). NO has been previously implicated in tumor biology. Previous studies have demonstrated that the expression level and activity of iNOS correlates with the histological grade of malignancy in human gynecological (21), breast (22), central nervous system (23) and lung cancers (24). iNOS activity and the resulting NO concentrations have been demonstrated to contribute to tumor progression by mediating tumor vascularization and tumor blood flow (21). iNOS was also induced in human colon adenocarcinoma, ovarian and glioblastoma cell lines in response to cytokine stimulation (21). The enhanced expression of iNOS in human colon carcinoma correlates with tumor growth and vascular invasion and may be indicative of the survival potential of cells (8). 
Induction of iNOS expression in HT-29 cells by a mixture of $I F N-\gamma, I L-1 \alpha$, and TNF- $\alpha$. Fig. 2 shows that the induction of iNOS expression in HT-29 cells by $100 \mathrm{U} / \mathrm{ml} \mathrm{IFN}-\gamma, 10 \mathrm{ng} / \mathrm{ml}$ IL- $1 \alpha$ and $25 \mathrm{ng} / \mathrm{ml} \mathrm{TNF-} \alpha$. iNOS was not detected in the absence of the cytokines. Treatment of the cells with Cnidii Rhizoma reduced the expression of iNOS in a dose-dependent manner (Fig. 2). The present study also demonstrated that 1400W inhibited cytokine-induced iNOS expression.

Invasiveness of HT-29 cells. Transwell plates were used to measure the invasive properties of cells following stimulation with $100 \mathrm{U} / \mathrm{ml}$ IFN- $\gamma, 10 \mathrm{ng} / \mathrm{ml}$ IL- $1 \alpha$ and $25 \mathrm{ng} / \mathrm{ml}$ TNF- $\alpha$. The invasion of HT-29 cells through Matrigel was significantly increased by treatment with cytokines (Fig. 3). Cnidii Rhizoma inhibited the invasiveness of cytokine-treated HT-29 cells through the Matrigel-coated membrane in a concentration-dependent manner (Fig. 3). The invasiveness of cells was inhibited by treatment with $1400 \mathrm{~W}$, an iNOS inhibitor, which confirms that iNOS contributes to the process of tumor cell invasion. $1400 \mathrm{~W}$ is an irreversible inhibitor of human iNOS, as well as a weaker and reversible inhibitor of human nNOS and eNOS. The potency and selectivity of $1400 \mathrm{~W}$ to iNOS in vitro and in vivo is increased compared with any other described iNOS inhibitor (25). The present study demonstrated that $1400 \mathrm{~W}$ inhibited NO production (Fig. 1C) and iNOS expression (Fig. 2) in HT-29 cells. Inhibition of NO production by $1400 \mathrm{~W}$ was accompanied by a reduction of HT-29 cell invasion through the Matrigel (Fig. 3). The present study revealed that cytokine treatment increased NO production in HT-29 cells. Cytokines further enhanced the invasiveness of the HT-29 cells. The present results suggest that endogenous NO production induced by cytokines increases the invasion of the human colorectal adenocarcinoma HT-29 cells. In the HT-29 cell Matrigel assay, the inhibition of invasion caused by treatment with $1400 \mathrm{~W}$, the most selective iNOS inhibitor, demonstrated the involvement of iNOS. The cytokine-stimulated invasion of HT-29 cells was not completely abolished by $1400 \mathrm{~W}$, which indicates that other mechanisms may also induce invasion, in addition to the iNOS/NO pathway.

MMP-2 activity in HT-29 cells. MMP-2 is one of the key enzymes involved in the degradation of the backbone of the cellular basement membrane, type IV collagen (26). To determine the activity of MMP-2, gelatin zymography was conducted using the conditioned medium, which was collected and measured following the treatment of cells for $24 \mathrm{~h}$ with the cytokines, and pretreatment with Cnidii Rhizoma or 1400W. MMP-2 activity in HT-29 cells was increased by the treatment of cytokines (Fig. 4). At a concentration of $5 \mathrm{mg} / \mathrm{ml}$, Cnidii Rhizoma pretreatment inhibited cytokine-induced MMP-2 activity (Fig. 4). An association was observed between a decrease in MMP-2 levels in HT-29 cells and a reduction in invasiveness. MMP-2 activity was also inhibited by $1400 \mathrm{~W}(0.5 \mathrm{~mm})$, which indicates that iNOS contributes to the induction of MMP-2 activity (Fig. 4). MMPs are significant in tumor invasion and metastasis through the proteolysis of several extracellular matrix proteins and are overexpressed during tumor progression. The present study reveals that pro-inflammatory cytokines induce NO production, iNOS expression and the invasiveness of human colorectal adenocarcinoma HT-29 cells, whilst pretreatment with Cnidii Rhizoma inhibited these processes. The present results may provide sufficient information for the further development of Cnidii Rhizoma as an antitumor metastatic agent against colon cancer in animal studies and later in human clinical trials.

In conclusion, this study revealed that pro-inflammatory cytokines induce NO production, iNOS expression and invasiveness of human colorectal adenocarcinoma HT-29 cells. In addition, pretreatment with Cnidii Rhizoma inhibited cytokine-mediated NO production, iNOS expression and invasiveness of HT-29 cells. Therefore, future animal studies and subsequent human clinical trails are required to investigate the potential antitumor and antimetastatic effects of Cnidii Rhizoma against colon cancer. In addition, considering the designing of appropriate strategies for an intervention, further studies regarding the active components of Cnidii Rhizoma are also required to investigate the mechanisms regulated by Cnidii Rhizoma.

\section{Acknowledgements}

This study was supported by the Korea Research Foundation Grant funded by the Korean Government (MOEHRD, Basic Research Promotion Fund; no. KRF-2005-075-C00024).

\section{References}

1. Choudhari SK, Chaudhary M, Bagde S, Gadbail AR and Joshi V: Nitric oxide and cancer: a review. World J Surg Oncol 11: $118,2013$.

2. Förstermann U and Sessa WC: Nitric oxide synthases: regulation and function. Eur Heart J 33: 829-837, 837a-837d, 2012.

3. Tanese K, Grimm EA and Ekmekcioglu S: The role of melanoma tumor-derived nitric oxide in the tumor inflammatory microenvironment: its impact on the chemokine expression profile, including suppression of CXCL10. Int J Cancer 131: 891-901, 2012.

4. Raina K, Agarwal C and Agarwal R: Effect of silibinin in human colorectal cancer cells: targeting the activation of NF-kappaB signaling. Mol Carcinog 52: 195-206, 2013.

5. Robert J: Biology of cancer metastasis. Bull Cancer 100: 333-342, 2013 (In French)

6. Khokha R, Murthy A and Weiss A: Metalloproteinases and their natural inhibitors in inflammation and immunity. Nat Rev Immunol 13: 649-665, 2013.

7. Chaudhary AK, Pandya S, Ghosh K and Nadkarni A: Matrix metalloproteinase and its drug targets therapy in solid and hematological malignancies: an overview. Mutat Res 753: 7-23, 2013.

8. Langenskiöld M, Ivarsson ML, Holmdahl L, et al: Intestinal mucosal MMP-1 - a prognostic factor in colon cancer. Scand J Gastroenterol 48: 563-569, 2013.

9. Haranaka K, Satomi N, Sakurai A, et al: Antitumor activities and tumor necrosis factor producibility of traditional Chinese medicines and crude drugs. Cancer Immunol Immunother 20: $1-5,1985$

10. Onishi Y, Yamaura T, Tauchi K, et al: Expression of the anti-metastatic effect induced by Juzen-taiho-to is based on the content of Shimotsu-to constituents. Biol Pharm Bull 21: 761-765, 1998.

11. Kwak DH, Kim JK, Kim JY, et al: Anti-angiogenic activities of Cnidium officinale Makino and Tabanus bovinus. J Ethnopharmacol 81: 373-379, 2002.

12. Garvey EP, Oplinger JA, Furfine ES, et al: $1400 \mathrm{~W}$ is a slow, tight binding, and highly selective inhibitor of inducible nitric-oxide synthase in vitro and in vivo. J Biol Chem 272: 4959-4963, 1997.

13. Menchén LA, Colón AL, Moro MA et al: N-(3-(aminomethyl) benzyl)acetamidine, an inducible nitric oxide synthase inhibitor, decreases colonic inflammation induced by trinitrobenzene sulphonic acid in rats. Life Sci 69: 479-791, 2001. 
14. Mertas A, Duliban H, Szliszka E, et al: N-[3-(aminomethyl)benzyl] acetamidine $(1400 \mathrm{~W})$ as a potential immunomodulatory agent. Oxid Med Cell Longev 2014: 491214, 2014.

15. Bernard WS and Christopher PW: World Cancer Report 2014 International Agency for Research on Cancer, World Health Organization, Lyon, France, 2014.

16. Center MM, Jemal A, Smith RA and Ward E: Worldwide variations in colorectal cancer. CA Cancer J Clin. 59: 366-378, 2009.

17. Fleming M, Ravula S, Tatishchev SF, Wang HL: Colorectal carcinoma: Pathologic aspects. J Gastrointest Oncol 3: 153-173, 2012.

18. Kim M, Li YX, Dewapriya P, et al: Floridoside suppresses proinflammatory responses by blocking MAPK signaling in activated microglia. BMB Rep 46: 398-403, 2013.

19. Green LC, Wagner DA, Glogowski J, et al: Analysis of nitrate, nitrite, and $[15 \mathrm{~N}]$ nitrate in biological fluids. Anal Biochem 126 131-138, 1982.

20. Hwang BM, Chae HS, Jeong YJ, et al: Protein tyrosine phosphatase controls breast cancer invasion through the expression of matrix metalloproteinase-9. BMB Rep 46: 533-538, 2013.
21. Thomsen LL and Miles DW: Role of nitric oxide in tumour progression: lessons from human tumours. Cancer Metastasis Rev 17: 107-118, 1998

22. Oktem G, Bilir A, Selvi N, et al: Chemotherapy influences inducible nitric oxide synthase (iNOS) and endothelial nitric oxide synthase (eNOS) activity on 3D breast cancer cell line. Oncol Res 16: 195-203, 2006.

23. Broholm H, Rubin I, Kruse A, et al: Nitric oxide synthase expression and enzymatic activity in human brain tumors. Clin Neuropathol 22: 273-281, 2003.

24. Ramasamy K, Dwyer-Nield LD, Serkova NJ, et al: Silibinin prevents lung tumorigenesis in wild-type but not in iNOS-/- mice: potential of real-time micro-CT in lung cancer chemoprevention studies. Clin Cancer Res 17: 753-761, 2011.

25. Babu BR and Griffith OW: Design of isoform-selective inhibitors of nitric oxide synthase. Curr Opin Chem Biol 2: 491-500, 1998.

26. Bauvois B: New facets of matrix metalloproteinases MMP-2 and MMP-9 as cell surface transducers: outside-in signaling and relationship to tumor progression. Biochim Biophys Acta 1825: 29-36, 2012. 